Начо Димитров

Bułgarska Akademia Nauk

nacho79@abv.bg

\title{
Трудовая мобильность каракачан в Болгарии - условия и мотивация
}

\begin{abstract}
Aвstract: Dimitrov Načo, Trudovaja mobilnost karakačan v Bolgarii-uslovija i motivacija (Labor Mobility of the Karakachans in Bulgaria - Circumstances and Motivation). „Poznańskie Studia Slawistyczne" 8. Poznań 2015. Publishing House of the Poznań Society for the Advancement of the Arts and Sciences, pp. 301-314. ISSN 2084-3011.

The term migration is used to describe a type of human behavior with immediate social, cultural, economic and political consequences. The researched cross-border labor mobility of the Karakachans in Bulgaria in the post socialist period affects more than $90 \%$ from the Karakachanfamilies in only a few years. This problem is pressing concerning the protectional Greek policy towards the Karakachan community from the beginning of the 1990s and the following mutual related migratory and identity-processes. Subjects of the present research are the Karakachans in Bulgaria, the Bulgarian people married to Karakachans and children from mixed marriages. The topics of the research include the various circumstances and factors for their labor mobility in Greece after 1989. The basic aim of this work is to explain the problem about the origin of researched labor mobility, which should answer the questions why it is possible and very probable. As a result, the social-economic, political and cultural circumstances which are important for the origin and the development of the labor mobility of the Karakachans in Bulgaria since 1989, are being depicted and investigated here.
\end{abstract}

KEYwORDs: cross-border labor mobility; small ethnic group; politic; economy; adjustments

Политические и социально-экономические изменения в Болгарии после 1989 года сопровождались тяжелым хозяйственным кризисом, высокой безработицей и интенсивыми миграционными процессами. Открытие границ привело к разным формам трансграничной мобильности, охватившей значительную часть населения. Вскоре после перемен члены одной из пятнадцати этнических и религиозных общностей в Болгарии - каракачаны, в отличие от остальных болгарских граждан, получили легкий доступ к входным визам в Республику Грецию. Это обусловило возникновение трудовой мобильности, которая всего за несколько лет охватила значительную часть членов 
общности. Для большинства из них трансграничная трудовая мобильность оказалась не просто дополнительной возможностью, но основной стратегией жизненной реализации. Как показывают данные полевого исследования, осуществленного автором в 2012-2013 годах, всего за несколько лет почти не осталось каракачанских семей, не затронутых трудовой мобильностью.

Объектом настоящего исследования являются каракачаны в Болгарии ${ }^{1}$, также болгары/болгарки, которые состоят в браке с каракачанами, дети этих смешанных браков. Предметом исследования являются разнообразные условия и факторы их трудовой мобильности в Грецию после 1989 года. Основной целью работы является освещение проблемы возникновения исследованной трудовой мобильности, в том числе, ответы на вопросы почему и как она стала возможной и почему она очень вероятна. Будут рассмотрены социально-экономические, политические и культурные условия, ведущие к возникновению и развитию трудовой мобильности каракачан в Болгарии после 1989 года.

Каракачаны - последние номады скотоводы в Юго-Восточной Европе. В последние 25 лет их численность в Болгарии варьирует, по разным источникам, от около 5000 до около 14 000-15 000 человек (Пимпирева 1998б: 12). Каракачаны - восточные православные християне, чей говор относится к северным диалектам новогреческого языка. В наши дни смешанные браки с болгарами - православными христианами, являются чем-то обычным. Несмотря на интеграционные процессы, которые имеют место после потери каракачан своей социально-экономической специфики и пространственной изоляции и после окончательного перехода к оседлому образу жизни в конце 1950-х годов, в период социализма каракачанам удалось сохранить сознание этнической общности с собственным языком, обычаями и представлениями об общем происхождении и историческом прошлом, что после 1989 года нашло выражение в создании по местам каракачанских обществ, объединившихся на принципах федерализма,

\footnotetext{
${ }^{1}$ Следует уточнить, что сегодня каракачаны живут в Болгарии, а большая часть из них - в Греции (Пимпирева 1998б: 7), но те, что в Греции, известные как „саракацаны” не являются объектом нашего исследования.
} 
с местонахождением в Сливене (Федерация культурно-просветительских обществ каракачан в Болгарии).

\section{Push/pull факторы}

После 1989 года большая часть каракачан ищет временную и/или сезонную работу в Греции. Мотивация трудовой мобильности обусловлена факторами на макро-, мезо- и микроуровне, которые по своему характеру могут быть как push/pull, так и способствующие/препятствующие миграции. Освещение этих факторов дает возможность рассматривать трудовую мобильность в более общем социально-экономическом и политическом контексте так называемого „перехода”. На процессы в Болгарии после 1989 года можно смотреть по-разному. Ключевыми и бесспорными стали, например, понятия „мирный переход и этнический мир, демократия, рыночная экономика и европейская ориентация" (Райчев, Стойчев 2008: 29). О переходе можно думать и как о „дифференциации элит, конверсии обесценившихся политических капиталлов в экономические капиталлы" или как о трансформации собственности из государственной в частную путем проведения приватизации и реституции, без соблюдения заранее договоренных правил (Райчев, Стойчев 2008: 179, 39, 45). В государстве, относимом к так называемым „low trust societies” (Roth 2005: 49), где доверие больше персонифицировано, чем социально, потому что строится на связях родства и знакомства, нежели на отношениях между гражданами и институциями, после 1990-х годов особенно важной становится трансформация клиентелизма (Беновска-Събкова 2001; см. также Kaser 2005): отпадает принцип ,доступы/статусы за счет вещей”, остаются в силе только „деньги за счет доступа (коррупция)” и „доступ за счет доступа” (Райчев, Стойчев 2008: 90).

В 1990-х годах таким образом очерченные трансформации привели к драматическим, на самом деле, для большей части населения процессам, которые, по сути, представляли собой упомянутые push факторы. Речь идет о возникновении острого социального неравенства, которое заняло не меньше места, чем демократизация, в массовом представлении о времени перехода. Это социальное неравенство, 
в сущности, равно обеднению, высоким процентам безработицы и т.д., иными словами - стремительному снижению качества жизни, вследствие „отсутствующей институциональной рамки и селективного применения законов” (Minev 1999: 334). В начале XXI века, по сравнению с 1980-ми годами, Болгария выглядела следующим образом: безработица „возрастает с 0 до официально около $20 \%$, реально - до $25 \%(\ldots)$, и ни разу не падает ниже $12 \%$, а в целых регионах прочно остается на уровнях около $30 \%$; промышленное производство снижается на 40-50\%; реальная рабочая зарплата падает на 70-75\%; из года в год уменьшается число отдыхающих - с 40\% на 10\%" (Райчев, Стойчев 2008: 97, 109, 112). „Всего за 10 лет дифференциация достигла ужасающих уровней: «верхние» 8\% потребителей потребляют столько, сколько «нижние» 73\%" (Райчев, Стойчев 2008: 107). В 1997 году потребление снизилось на 70\% по сравнению с 1989 годом. По данным официальной статистики о среднем месячном доходе за 1992 год около 50\% населения Болгарии жило под социальным минимумом. В 1993 году этот процент поднимается на десять пунктов, а по оценкам Министерства труда и социальных отношений в 1994 году под этой чертой находятся $80 \%$ болгар. Если под „социальным минимумом” понимать ограниченный доступ к более широкому набору товаров и социальных услуг, как здравоохранения и образования, то нижняя граница бедности маркирует условия, необходимые для физиологического выживания индивидов. Речь идет о так называемом „экзистенциальном минимуме”, под чертой которого, по данным Национального статистического института, в 1993-1994 годах живет 30\% людей, страдающих недоеданием (Minev 1999: 322, 326). Покупательная способность уменьшается такими темпами, что в 1994 году равняется 50\% покупательной способности 1990 года. Реальные доходы семей до 1996 года понижаются на 65\%. Снижение качества жизни не просто утверждение, его можно проследить по целому ряду социальных показателей первой половины 1990-х годов: уменьшается коэффициент репродуктивности населения, в частности, изза повышенного уровня смертности; ухудшается состояние системы здравоохранения; значительно урезываются средства на социальное обеспечение, например, на пособия для детей и матерей; годовой рост числа пенсионеров возрастает втройне из-за права раннего ухода на 
пенсию, которое используется в качестве буфера против возрастающей безработицы; в то же время размер средней пенсии уменьшается наполовину в рамках четырех лет и остается постоянно под уровнем минимума, необходимого для существования (Minev 1999: 326, 327).

Около 10\% населения сохранило уровень жизни до 1990 года, у других 7-8\% наблюдается значительный скачок доходов, а в руках менее $1 \%$ людей сосредоточились огромные финансовые ресурсы и экономическая власть. Определение „массового обеднения” относится к остальным 80\% населения (Minev 1999: 324).

Эти изменения в социальной сфере вряд ли нуждаются в подробных объяснениях. Достаточно сказать, что „в таких странах, как Румыния и Болгария, существуют небольшие группы людей, которые разбогатели быстро, но нельзя сказать, что обогащение их является легитимным и законосообразным" (Фотев 2009: 107). Это видно и из общественных настроений: в Болгарии почти 50\% людей считают несправедливость в обществе основной причиной социального неравенства. Для сравнения, в Греции удельный вес респондентов с таким мнением 24\% (Фотев 2009: 107). Частью последствий всего выше описанного и одновременно с этим частью того, что мы понимаем под „снижением качества жизни”, являются и оформившиеся представления и ожидания людей (push фактор на микроуровне), а их можно описать как разочарование, неуверенность, страх будущего" (Minev 1999: 330).

Из-за отсутствия различий в образовании, квалификации и трудовой занятости каракачан по сравнению с остальным болгарским населением (Пимпирева 1998а: 256), их общность затронута этими процессами в неменьшей степени, чем остальных болгар.

В то же время в Греции отмечается положительное экономическое развитие, начавшееся еще во второй половине 70-х годов и дополнительно набравшее скорость после присоединения страны к европейскому экономическому сообществу (ЕЭС) в 1981 году, когда „к стране потекли европейские инвестиции” (Вълчинова 1998: 215-216), а „греческий рынок труда непрерывно расширяется" (Димитрова 2011: 111). Это, разумеется, процессы, которые также требуют времени. Как „катастрофические” характеризуются первые два года членства Греции в ЕЭС, из-за спада в производстве, высокой инфляции и высоких 
уровней импорта (Никова 2012: 196). В первые десять лет членства Греция не сумела догнать остальные страны сообщества. В 1980 году валовой внутренний продукт страны на душу населения равнялся 58\% среднего для ЕЭС, а в 1992 году снизился до 52\%. Несмотря на это, правительство ПАСОК добилось „скачка доходов” и осуществило „щедрые социальные программы и расходы в областях образования, здравоохранения, инфраструктуры”. Это, однако, произошло, в основном, благодаря европейским деньгам: „Над Грецией высыпался настоящий золотой дождь” из 0,6 млрд. долларов в 1982 году, 2,5 млрд. долларов в 1992 году и еще 19,2 млрд. до 1999 года (Никова 2012: 196-197). В 1998 году ЕЭС приняло решение включить Грецию в еврозону, что привело к девальвации драхмы на 12\%. С начала 2001 года решение вошло в силу и начался период „беспрецедентного развития - темпы роста в два раза превзошли средних по Союзу, риск обесценивания валюты исчез, что сделало возможным долгосрочное планирование бизнеса, дешевые кредиты и рост потребительского спроса", а это, со своей стороны, логически оказало положительное влияние на общественные настроения: „Высокие темпы роста (4\% в среднем за год) устраняют большинство существующих внутренних противоречий - между левыми и правыми, между городом и селом, между местными и эмигрантами и т.д.” (Никова 2012: 199).

Таким образом, несмотря ни на что, в середине 1990-х годов греческая экономика характеризуется как „слабая”, а управление Костаса Симитиса (1996-2004) - как время „решительных мер по оздоровлению фискальной и денежной политики" (Никова 2012: 197, 198), в первом десятилетии XXI века „по сравнению со своими обанкротившимися соседями Греция выглядит настоящей экономической силой” (Никова 2012: 208). Следовательно, не случайно то, что еще с начала 1990-х годов эта страна „становится целью номер один для экономической эмиграции” (Вълчинова 1998: 216) из Болгарии. Число работающих болгар в южной соседней стране в 2002 году равняется 100 тысячам человек, в 2004 году оно возрастает на 200 тысяч, а в 2006 году - на 300 тысяч (Райчев, Стойчев 2008: 117).

Приведенная выше статистика имеет совсем реальные измерения для каракачан, работающих за рубежом. Действительно, для большинства из них потеря рабочего места и трудность или невозможность 
нахождения новой работы в Болгарии становятся отталкивающим фактором: „Смутное было время и начали сокращать людей. Стали все уничтожать" (ठ̊, 55 - ИЭФЭМ-АЭИМ 980-III: 254). Однако, очень часто безработица не является единственной причиной, она упоминается наряду с низкими доходами: „Здесь не только работы не было, но на много ниже была и оплата труда" (, 50 - ИЭФЭМ-АЭИМ 980III: 6). А большинство полевых примеров дают основание утвержать, что не тяжесть безработицы явялется основным фактором миграции, а оплата труда здесь и там. Больше всего имеется случаев, когда к моменту первого отъезда на работу в Грецию, респонденты были заняты трудовой деятельностью в Болгарии, но их привлек шокирующе высокий уровень оплаты труда: „Поработаешь там два месяца, получаешь столько, сколько здесь за два года работы не можешь получить" (ठิ, 57 - ИЭФЭМ-АЭИМ 980-III: 157).

Рассматривая тяжесть безработицы и доходы, не следует забывать значение представлений и ожиданий. С начала перемен в Болгарии социально-экономическая ситуация непрерывно ухудшается быстрыми темпами, страна переживает многие острые кризисы (1996-1997 гг.), „разочарования и отрезвления” (Калинова, Баева 2006), когда становится ясно, что быстрого улучшения не следует ждать. В качестве ключевых понятий для общественных настроений этого периода можно отметить следущие: „неопределенность” и „бесперспективность”. В то же самое время, с самого начала трудовой мобильности, еще в 1990 году, каракачаны понимают, что в Греции их ждут и принимают, что затруднения, связанные с поиском работы, не так уж и велики, особенно, если учесть ожидаемое трудовое вознаграждение. Учитывая роль представлений, настроений и ожиданий, можно утверждать, что влияние перемен на жизнь каракачан, особенно на тех, кто занимался овцеводством до 1989 года, имело (имело бы, если бы не трудовая мобильность!) еще более негативный эффект. Причина в том, что каракачаны-скотоводы очень трудно приняли бы жизнь в тяжелых условиях после 1989 года. Это было вызвано обстоятельством, что, грубо говоря, они привыкли зарабатывать и получать больше остальных, а это неизбежно сформировало определенные представления, ведущие к определенным поведенческим реакциям: „До 1990 года наши каракачаны работали в основном в ТКСХ и АПК пастухами. (...) 
Животноводство трудное, но мы зарабатывали больше денег” (ðે, 57 ИЭФЭМ-АЭИМ 980-III: 153).

По той же логике эффекты трудовой мобильности еще в первые годы формируют представления, которые обуславливают дальнейшую занятость за рубежом. Таким образом, получается замкнутая мыслительная конструкция, которая оказывается препятствием для прекращения трудовой мобильности: „Мы с мужем думаем остаться здесь работать, но не знаем, сможем ли справиться с 300 левами. Я не знаю, как другие люди справляются. Мы так не привыкли - жить на 300 левов. Это смешные деньги. Потому что для одного ребенка расходы намного больше 300 левов. Я так думаю, потому что мои дети не привыкли жить в лишениях. Но есть люди, справляются. Мне это кажется невозможным, совершенно невозможным" (, 40 - ИЭФЭМАЭИМ 980-III: 214-215).

И опять через ту же призму можно рассматривать представления респондентов о соотношении „рабочего времени-заработанных денег”, а также о способе расценки свободного времени: „Сейчас и я останусь здесь, сидеть буду в кафе. Могу туда поехать (в Грецию прим. авт.) на 30 дней и потом - опять все время сидеть в кафе, вместо того, чтобы работать здесь охранником где-нибудь 12 месяцев в году. Поедем с бабушкой на 30 дней туда, заработаю столько же денег, сколько здесь берут за один год охранники" (ふ,, 70 - ИЭФЭМ-АЭИМ 980-III: 176).

Прямые последствия возможности работы в Греции самые разнообразные, но в основном, определяются способами использования заработанных средств. Все они, однако, имеют одно общее качество - являются мотивирующим фактором. Во-первых, как это уже было отмечено, следует упомянуть то, что каракачаны переживают более безболезненно острые кризисы 1990-х годов: „Голодных лет мы както не помним" (ð, , 40 - ИЭФЭМ-АЭИМ 980-III: 215). Более того, они оказываются среди немногих людей в Болгарии, имеющих доступ к люксозным и/или дефицитным товарам того времени: „Особенно в первые годы - целые картонные коробки, полные шоколада, всяких фруктов, грейпфрутов, мандаринов. (...) Ты, наверное, помнишь какие здесь очереди стояли, чтобы купить все это" (†, 45 - ИЭФЭМ-АЭИМ 980-III: 123). 


\section{2. Способствующие факторы}

Для мигрантов рассмотренные выше основания для миграции имеют реальные параметры, представляющие собой благоприятствующим дальнейшей трудовой мобильности фактором. Во-первых, это соотношение доходов и расходов трудовых мигрантов. Респонденты утверждают, что в начале 1990-х годов зарабатывали между 4000 и 8000 драхмами, в зависимости от вида трудовой деятельности, причем самые высокие доходы имели работавшие в строительстве, где мастера получали до 12000 драхм. В сельском хозяйстве очень часто труд оплачивался не за день, а в зависимости от норматива, из-за чего общая заработанная за день сумма могла варьировать, но не отличалась драматично от размера среднего заработка. Сравнение показывает, что в 1990-1991 годах это в 9 раз больше размера средней заработной платы в Болгарии. Введение евро привело к некоторому обесцениванию денег, но это не отразилось особенно на разнице в размерах доходов в Болгарии и Греции. Важным элементом формирования доходов является и возможность работать сверхурочно, причем дополнительно отработанные часы очень хорошо оплачиваются: ,Часы сверх 8 (рабочих - прим. авт.) оплачивались больше. Намного больше. Я помню, за день получил более 60 евро со сверхурочными" (q, ок. 45, рассказывает о работе на мясокомбинате - ИЭФЭМ-АЭИМ 980-III: 121). К доходам мигрантов следует добавить и страховые взносы, которые они получают, независимо от того Институт страхования ли это делает - легально, или сам работодатель выдает деньги работавшему.

Когда мне вносят страховые взносы, добавляют плюс 10 евро. Четыре месяца спустя я иду в Страховой институт со своей страховой книжкой и паспортом, и они мне выдают деньги. Скажем, у меня за три месяца 100 дневных заработков, по 10 евро - мне 1000 евро возвращают, дают эти деньги мне. Их внес работодатель. (...) А если ты работаешь без обеспечения, страховки тебе не вносят, ты договариваешься на 20, 30, 50 евро и получаешь то, о чем договорился, берешь и уезжаешь” (ふ,, 67 - ИЭФЭМ-АЭИМ 980-III: 92).

Расходы мигрантов в большей степени зависят от них самих, по сравнению с размером дневного заработка или с нормированной оплатой. Существует несколько основных способов подхода мигрантов к управлению собственным бюджетом. Одна из стратегий 
минимизирования расходов - оптимальное использование короткого срока визы: „Когда давали визу сроком на два месяца, мы старались использовать ее максимально. Если уедешь раньше, теряешь ее, опять нужно в Софию ездить, в очередях стоять" (ð,, 52 - ИЭФЭМ-АЭИМ 980-III: 98). Другая основная стратегия минимизирования расходов - кооперирование финансовых средств, с целью разделения расходов на транспорт, жилье и другие потребности. Мигранты заранее, еще до отъезда, запасаются всем необходимым, особенно пищевыми продуктами - в количествах, которые можно разместить в автомобиле: „Взяли с собой одеяло, ковры, консервы, брынзу, сыр - преимущественно такие продукты, которые дольше хранятся. На 10 дней нам хватило, вообще и не входили в магазины что-либо покупать" (ふ,, 52 - ИЭФЭМ-АЭИМ 980-III: 103). Последняя подобная стратегия заключается в том, чтобы обеспечить себе дешевое и бесплатное пребывание - очень часто мигранты в 1990-х годах ночевали в палатках или автомобилях.

Самое бесспорное условие исследуемой трудовой мобильности это открытие границ как следствие политических изменений в Болгарии в ноябре 1989 года. Однако его не следует переоценивать, потому что оно на долгий период времени является однонаправленным. Граница односторонне и очень выборочно пропускала: ты можешь легко уехать из Болгарии, потому что никто тебя не останавливает, но не так легко можешь въехать в другую страну, потому что туда не пускают, если ты не выполнил определенных условий. Для пребывания в Греции каракачанам, также членам смешанных браков, выдают визы с преимуществом. Определяющей в этой связи является роль иммиграционной политики Греции с начала 1990-х годов, обеспечивающей более легкий доступ в страну грекоязычного населения из стран Балканского полуострова, Малой Азии и бывшего Советского Союза. Легкий доступ к визам - самый важный благоприятствующий миграции фактор. Если бы его не было, трудовая мобильность каракачан в Болгарии в постсоциалистический период, наверное, не отличалась бы от миграционных движений остальных болгар, потому что не были бы столь предопределены направление и временные параметры миграции. Это, может быть, лучший пример различия между привлекающими и благоприятствующими факторами: если высокие доходы 
в принимающей стране по сравнению с теми в посылающей делают рассматриваемую трудовую мобильность в направлении Греции имеющей смысл и поэтому объяснимой, то легкий доступ к входным визам делает ее не только возможной, а прямо-таки легкой и следовательно - очень вероятной.

В связи с получением виз особенно важной для общности в Болгарии оказывается Федерация каракачанских обществ, которая играет роль гаранта перед греческим консульским отделом о каракачанском происхождении своих членов. Достаточным доказательством принадлежности к каракачанской общности является членство в местном обществе. Процедура выдачи виз сделана с целью облегчения положения каракачан. В начале каждый желающий ездит лично в посольство в Софии или в генеральное консульство в Пловдиве, но через некоторое время представителю соответствующего местного общества поручается отвезти паспорта в ближайшую службу и забрать их обратно с уже готовыми визами.

Значительна роль языка в преодолении конкуренции на трудовом рынке Греции: „Единственная проблема была, что болгар не брали на работу, потому что не владели языком. Все ходили с кем-нибудь из каракачан” (ふૈ, 59 - ИЭФЭМ-АЭИМ 980-III: 72). Язык очень важен и во взаимоотношениях с работодателями и коллегами на рабочем месте. Показателен следующий пример о трудностях человека, не владеющего языком. Речь идет о болгарине, женатом на каракачанке: „Пока она (супруга - прим. авт.) была со мной, она мне переводила. А когда уехала - стало плохо! Хочешь не хочешь, должен учить. Говорят, иди налево, я иду направо; неси мотыгу, я ношу тесло" ( АЭИМ 980-III: 137).

Выбор населенных пунктов в Греции связан с возможностями, которые они предлагают, а также с их пространственной близостью к двум пограничным контрольно-пропускательным пунктам Болгарии - Ново село (сегодня Капитан Петко войвода) и Кулата. Так, для большой части каракачан предпочитаемыми дестинациями для трудовой миграции стали районы Комотини, Драмы, Аспровальты и, прежде всего, Салоники и его окрестностей. Роль пространственной удаленности между посылающей и принимающей страной бесспорна, особенно что касается выбора дестинаций и частоты поездок 
и времени пребываний. В данном случае Греция имеет бесспорное преимущество быть соседней Болгарии державой.

В заключении можно подчеркнуть роль самых важных благоприятствующих миграции факторов (виз и языка) для облика трудовой мобильности, на базе сравнения с трудовой мобильностью этнических болгар в Греции. Как рассказывают респонденты, „многие болгары остались там жить, в то время как каракачаны не остались там, кроме тех, кто там женился, хотя это и очень редкие случаи" (О̃, 39 - ИЭФЭМ-АЭИМ 980-III: 231). Как раз то, что болгары не владеют языком и трудно получают визы, превращает их миграцию в долгосрочную или в эмиграцию. Каракачаны легко получают визы с правом работы, следовательно, они могут когда им захочется въезжать в страну и выезжать из нее, независимо от того, легально ли они работают или нет; они владеют языком, а это означает, что им легче найти себе работу. В то же время болгары, раз уже въехавшие в Грецию, не выезжают, потому что потом им трудно снова пересекать границу. Однажды найдя себе работу, они, по возможности, не упускают ее, потому что располагают более ограниченным культурным (языком) и социальным (контактами) капиталами для нахождения другой работы.

\section{Литература}

Беновска-Събкова М., 2001, Политически преход и всекидневна култура, София. Вълчинова Г., 1998, Гърии, в: Общности и идентичности в България, съст. А. Кръстева. Петесктон София, с. 207-220.

Димитров Н., 2014, Трудова мобилност на каракачаните в България в постсоииалистическия период, София, дисертационно изследване.

Димитрова Т., 2011, Съвременни миграчиионни групи в Гъриия, София, дисертационно изследване.

Калинова Е., Баева И., 2006, Българските преходи 1939-2005, София.

Никова Е., 2012, Гъриия: десетилетие на възход и крушение, в: Балканите през първото десетилетие на 21. век, ред. А. Костов, Н. Екатерина, София, c. $195-220$.

Пимпирева Ж., 1998а, Каракачани, в: Общности и идентичности в България, ред. А. Кръстева, София, с. 243-259.

Пимпирева Ж., 1998б, Каракачаните в България, София. 
Пимпирева Ж., 2008, Каракачаните в постсоичалистическа България, в: В света на човека, ред. Д. Маджаров, С. Красимир, Сборник в чест на проф. д.и.н. Иваничка Георгиева, т. 1, Университетско издание „Св. Климент Охридски”, София, с. 83-95.

Райчев А., Стойчев К., 2008, Какво се случи? Разказ за прехода в България и малко след него, София.

Фотев Г., 2009, Ценности срещу безпорядък, София.

100-но Постановление на Министерския съвет от 15 март 1954 г. относно установяването на каракачаните на постоянно местожителство, в: Известия на Президиума на Народното събрание, бр. 25, година 5, 26.03.1954.

Интернет источники

$<$ http://censusresults.nsi.bg/Census/Reports/2/2/R9.aspx?OBL>, 22.11.2014.

$<$ http://www.karakachani.com/bg/home/celi.html>, 22.11.2014.

Архивные источники

ИЭФЭМ-АЭИМ 980-III

Kaser K., 2005, Klientelismus: Positive Potenziale und Risken eines tradizionellen Modells sozialer Beziehungen, в: Bilanz Balkan, пер. M. Daxner, P. Jordan, P. Leifer, K. Roth, E. Vyslonzil, Wien, s. 54-67.

Minev D., 1999, Armut und soziale Transformation, в: Bulgarien im Übergang. Sozialwissenschaftliche Studien zur Transformation, пер. H.L. Krämer, C. Stojanov, Bergisch Gladbach, s. 321-348.

Roth K., 2005, Institutioneles und persönliches Vertrauen. Südosteuropa auf dem schwierigen Weg in die Europäische Union, в: Bilanz Balkan, пер. M. Daxner, P. Jordan, P. Leifer, K. Roth, E. Vyslonzil, Wien, s. 47-53. 
